GLOBAL MEDICAL ETHICS

\title{
To have or to be: ways of caregiving identified during recovery from the earthquake disaster in Taiwan
}

\section{H-H Chiang, Z-Y Lu, S E Wear}

See end of article for

authors' affiliations

J Med Ethics 2005;31:154-158. doi: 10.1136/jme.2003.004101

Correspondence to

Hsien-Hsien Chiang,

Associate Professor,

Faculty of Nursing,

National Yang-Ming

University, No. 155, Li-

Nong St Sec. 2, Pai Tou,

Taipei, Taiwan 112;

hhchiang@ym.edu.tw

Received 25 March 2003

In revised form

6 October 2003

Accepted for publication

14 April 2004

\begin{abstract}
The aim of this article is to report the results of therapy sessions conducted with survivors of an earthquake that struck Luku Township in Nantou County, central Taiwan, in September 1999. The sessions explored survivors' feelings, interactions, and interpretations of the crisis, as well as their roles in post-earthquake relief efforts. The participants were teachers and administrators from four primary schools. The results indicated three distinct forms of caring, namely: encumbered caring, connected caring, and reflected caring. The findings were used to construct a framework for caregiver self-monitoring. They also suggest that therapy groups provide an inner space that self-regulates the frustrations arising from this type of experience, for both caregivers and survivors. The intrasubjective and intersubjective dialogues within the groups are essentially reflective practices for improving services and generating new knowledge about medical ethics.
\end{abstract}

E xtensive and increasing reflection on bioethical issues is now occurring in Taiwan and elsewhere in the East; part of this reflection has been based on review of the enormous bioethics literature from the West. However, this literature is viewed with caution for a number of reasons. First, generically, the concern is that such western thought may amount to another form of western imperialism. Secondly, much contemporary western bioethics proceeds in terms of an autonomy/individualist model that tends to clash fundamentally with the traditional family orientated ethic of the East, particularly in the still traditional Taiwanese cultures. Although issues concerning informed consent, truth telling, and paternalism have been discussed in Taiwan, the autonomy-based ethic of the West seems essentially to supplant a family orientated approach. Thus, the individualistic model of bioethics has been reflected upon, but hesitantly and sceptically.

One theme in western bioethics that is especially intriguing to us is the concept of caring. In essence, caring may be seen as a vehicle that could bridge eastern and western notions of bioethics and perhaps form a basis for overlapping agreement between the two perspectives. This is because the concept of caring seems to be used by certain western thinkers to avoid the overly individualistic, contractual or legal view of interactions between caregivers and patients. Instead of overemphasising rights and responsibilities, the notion of caring seems to be aimed at developing a more integrated, empathetic view of this relationship-one of sharing and partnership-that comports much better with traditional eastern thinking and current cultural mores. Thinkers concerned with nursing ethics identify the notion of caring as a way of relating to patients that is especially congenial to the instinctive experience of nurses.

As has been recognised, different forms of caring reflect different assumptions about personhood. Based on Confucius's interpretation of "person" as chun-tze, the "morally ideal person", Tsai pointed out that a person should be seen not only as a rational, autonomous agent but also as a relational, altruistic identity. ${ }^{12}$ Such a two-dimensional nature of personhood results in two ways of performing caregiving actions, involving a self-actualisation of caregivers in addition to ongoing participation in, and promotion of, the welfare of their clients. In some instances, caring can be more of an egocentric enterprise, where it is the needs of the caregiver, not the patient, that are met, not seldom to the harm of the patient. In order to ascertain the culturally specific nature of caring that has the potential to bridge western and eastern bioethics, we conducted a study to explore the nature, scope, and limits of this type of relationship between caregivers and care recipients, with reference to the immediate experiences of participants in group therapy for the earthquake survivors.

More specific to the study reported here, caring work in a clinical situation tends to focus on doing good, and to reflect less on the meaning of doing good. It is obvious that caring science has become increasingly orientated towards more humanistic thinking, but is not yet ready to work towards a deeper understanding of the complexities of caring. ${ }^{3}$ Schön recognised the factual complexity of professional work and explained the central role of reflection in professional action. He also pointed out that reflection in action is a means by which professionals make sense of the problematic nature of their practice, whereas reflection on action promotes learning from that experience. ${ }^{4}$

Caring for others is to respond with responsibility. This original ethical relationship is brought about by the face of the other person. ${ }^{5}$ The other, as a voice, as an address, as an appeal to one, is like a calling, which can induce intrasubjective and intersubjective dialogues by the conscious self. Chiang et al identified three kinds of intrasubjective dialogue based on analysing the nurse-patient relationship: complaining about others, blaming oneself, and exploring the mystery of the other. ${ }^{6}$ Complaining about others and blaming oneself are kinds of egocentric dialogue. Being curious about others keeps the mind open to the situation.

Group interactions with earthquake survivors could provide evidence for us to reflect on what is happening in caring work. Debriefing, a group-orientated intervention in which 
the major elements of a trauma are reviewed by the participants shortly after the event, has been recommended as a stress management technique. ${ }^{7-9}$ Mental health personnel in Taiwan have unreflectively used psychological debriefing to prevent psychological morbidity and aid the recovery process after the earthquake. For caregivers to offer assistance is to empathise with those experiencing pervasive feelings of community sadness. ${ }^{10}$ However, the caregiver who is less open minded to the situation, and whose approach is egocentric, may indirectly wound sufferers. The function of the "caregiver" becomes an attempt to heal or actualise oneself, rather than to help survivors to recover. It is easy to start providing care for a survivor as an object, in response to the "calling", without understanding the real meaning of caring for an object. To treat the other as an object, as something possessed by me, is to assume the status of ownership, of "having", which is to control or manipulate the other. ${ }^{11}$ A person in this position may not adequately differentiate the self and the other. To be oneself, differentiation between the self and the other would be helpful in respecting the other and being with them, when the caring may not be harmful and may be truly for the other. Caregiving behaviour extended to earthquake survivors has not been studied extensively. Thus, the research questions were:

- What kinds of caregiving were extended to the earthquake survivors?

- How have the caregiving activities affected the lives of the survivors?

- What are the essential characteristics of various caregiving practices?

\section{METHOD}

This qualitative study involved interpretive analysis of group dialogues and participant observations to illuminate caring experiences in the groups. The group dialogues were conducted for debriefing survivors of the earthquake, which occurred in 1999 and measured over 7 on the Richter scale. The therapeutic group met as a part of the project, "Health promotion program of Luku Township after 921 earthquake". ${ }^{12}$ Teachers and administrators from four primary schools in Luku Township in Nantou County, central Taiwan, participated in this study; one group session was held in each school. For the purposes of this study, the schools were designated A, B, C, and D. The therapy group for each school consisted of one 3-hour session. Students were brought together to participate in an art or activity class by the teachers in the therapy group.

Schools A and D were smaller than schools B and C, and schools B, C, and D had more than five collapsed classrooms. Schools B and D each had a student killed in the earthquake (table 1). Each group had 7-14 members, including school administrators and teachers who had the potential to empower other survivors, such as students and their families. Locations for group sessions were changed in some schools after the relocation of space at the initial group session (table 2). The topics discussed were derived from the dialogue facilitated by two group therapists, who moderated the sharing of feelings and perceptions in the aftermath of the earthquake.

The data collected included four sets of group process notes and the researchers' journal entries. During multiple readings of the data, caring appeared to be an important concept, but its presence varied according to the situation. Data were analysed from the three interwoven processes of hermeneutic interpretation: thematic analyses, interpretation of exemplars, and interpretation of paradigm cases. ${ }^{13}{ }^{14}$ The group
Table 1 Demographic data of primary schools involved in the therapy group

\begin{tabular}{|c|c|c|c|c|}
\hline & \multicolumn{4}{|c|}{ Group } \\
\hline & A & B & C & D \\
\hline No. teachers & 12 & 18 & 13 & 11 \\
\hline No. students & 95 & 200 & 201 & 90 \\
\hline $\begin{array}{l}\text { Damage to } \\
\text { buildings }\end{array}$ & Low & High & High & High \\
\hline $\begin{array}{l}\text { No. student } \\
\text { deaths }\end{array}$ & 0 & 1 & 0 & 1 \\
\hline
\end{tabular}

Table 2 Group structure characteristics

\begin{tabular}{|c|c|c|c|c|}
\hline & \multicolumn{4}{|l|}{ Group } \\
\hline & $\bar{A}$ & B & C & D \\
\hline Location & $\begin{array}{l}\text { Classroom } \rightarrow \\
\text { library }\end{array}$ & $\begin{array}{l}\text { Auditorium } \\
\vec{G}\end{array}$ & $\begin{array}{l}\text { Teacher's } \\
\text { office }\end{array}$ & $\begin{array}{l}\text { Playground } \\
\rightarrow \text { library }\end{array}$ \\
\hline $\begin{array}{l}\text { No. } \\
\text { members } \\
\text { Gender }\end{array}$ & 7 & 14 & 8 & 7 \\
\hline Male & 4 & 7 & 3 & 4 \\
\hline Female & 3 & 7 & 5 & 3 \\
\hline $\begin{array}{l}\text { School } \\
\text { principal } \\
\text { present }\end{array}$ & Yes & Yes & No & No \\
\hline
\end{tabular}

process notes and researchers' journals were reviewed for the status of difficulties and care. Before each case was examined in detail, an interpretative outline was formed, which was used to address the case in terms of the original research questions and through the categories of interest that arose in the data. Cross-case comparisons then continued throughout the interpretive process, focusing on the status of intrasubjective self and intersubjective interaction in caring. It was found that the earthquake stricken teachers exhibited the experiences of encumbered caring, connected caring, and reflected caring (defined below). The findings were validated by repeatedly reading and testing texts against proposed interpretations, and by presenting findings to health care workers and qualitative researchers for confirmation.

\section{FINDINGS}

Three qualitatively distinct caring practices were evident in this sample of therapeutic groups: encumbered caring, connected caring, and reflected caring (table 3). They are represented by the caregivers' orientation to the self, interaction, and Dasein (being-in-the-world). ${ }^{15}$

\section{Encumbered caring}

To care for others may constitute an occasion for satisfying the needs of the self, instead of allowing recipients to be themselves. This kind of caring can easily place care recipients in trouble.

\section{Caring inadvertently jeopardised the lives of care recipients}

In Group A, one member mentioned that his father was very angry about receiving phone calls from relatives. Concerned relatives tended to make frequent phone calls seeking information updates during aftershocks. By entering the house to answer the phone calls, the earthquake survivor, who still lived in tents in the yard, risked injury from the roof 


\begin{tabular}{|c|c|c|c|}
\hline Level of caring & Intrasubjective self & Intersubjective interaction & Dasein \\
\hline Encumbered caring & $\begin{array}{l}\text { Narcissistic self } \\
\text { Egocentric }\end{array}$ & $\begin{array}{l}\text { Fusion } \\
\text { Manipulation of others }\end{array}$ & To have/inauthentic \\
\hline Connected caring & $\begin{array}{l}\text { Actualised self } \\
\text { Recognition of other }\end{array}$ & $\begin{array}{l}\text { Reciprocity } \\
\text { Coexistence }\end{array}$ & $\begin{array}{l}\text { To be and to have } \\
\text { Undifferentiated }\end{array}$ \\
\hline Reflected caring & $\begin{array}{l}\text { Transcendent self } \\
\text { Mutuality }\end{array}$ & $\begin{array}{l}\text { Good to others } \\
\text { Common wellbeing }\end{array}$ & To be/authentic \\
\hline
\end{tabular}

collapsing. He said that when he was answering a phone call, a bookshelf fell near him. Therefore, he yelled to the relative, "I was almost killed just by taking your phone call." Caring behaviours tend to originate in the needs of caregivers, rather than care recipients. The concerned relatives made the phone calls to relieve their own anxiety. Earthquake survivors had to divide their energies between repeating the same stories to concerned relatives and organising life support for survivors. Thus, caregivers reflected: Who gains from the caring behaviours? How are the care recipients affected by the practices of caring?

\section{Caring disturbed the daily routine}

One member of group $\mathrm{C}$ expressed her anxiety about interruption of the school class schedule by the debriefing group. How students' learning had become impeded after the earthquake soon became an issue of discussion. One young teacher expressed the opinion that conducting classes had become difficult because disciplining students became a problem. One student had said to him: "I would rather have been killed in the earthquake than be in this class."

Encumbered caring was offered in response to survivors' traumas in the manner that satisfied the various needs of caregivers. The narcissistic self of the caregivers needed survivors as objects to fulfil their own unfinished business. Survivors were harmed further because caregivers used caring to compensate for their own emotional needs rather than those of the survivors. Hence, encumbered caring for others unavoidably results in more suffering for care recipients.

\section{Connected caring}

Caring for the other genuinely fits with the other's situation. Caregivers have the opportunity to perform their role and to be with the other.

\section{Dealing with being "too busy to share"}

Group members complained about the burden of their duties after the disaster. Members of one group talked about their anger because they were asked to clean up the campus immediately after the earthquake, rather than being allowed to attend to their own destroyed houses. One member of another group also stated that teachers were too busy reconstructing the campus to discuss their feelings about the earthquake. Group facilitators encouraged future regular group meetings for sharing and dialogue. The school nurse took the lead by proposing a packed lunch each Wednesday.

Connected caring promotes opportunities for connecting the intersubjective interaction and the intrasubjective self, while the arduous work and painful feelings that occupied survivors' lives after the earthquake separated them from others and from themselves. Therefore, group facilitators have an opportunity to experience some of the survivors' inner strength; caregivers meet survivors in a reciprocal relationship.
Dealing with being "too hurt to share"

Mourning for a student confirmed dead in the earthquake was observed in a group session. In the early stage of the session, members shared their anger about having no time to clean up their own houses. The discussion turned to their feelings about the loss of a student while group facilitators asked them about their feelings concerning the earthquake. After the mentor of the deceased student initiated the conversation about the student, several group members began to cry. Members provided support for each other by holding hands and embracing warmly.

After the group session, the chair of students' affairs expressed his astonishment at his colleagues' suffering and their ability to share their feelings about it. One school principal also stated that, "After the earthquake, many group meetings were held in the school. However, none of those meetings elicited as much reaction and feedback."

People are used to maintaining stable and controllable lives by isolating themselves from traumatic experiences. However, such isolation may break an individual's connections between the interpersonal or intrasubjective parts of the self. Group facilitators provided the time and space for members to connect and deal with their concealed emotions. Group members learned to connect with each other and their own mourning, instead of avoiding their emotions by being too busy or too hurt to share.

\section{Reflected caring}

This caring for the other is based on contextually regulating pre-existing ideas about helping activities. Caregivers are willing to step into the problem situation and are open to discovering the mysteries of others. This approach allows the self and the other to exist as themselves and does not try to control them. There are two kinds of reflected caring. One is reflection in action, which is reflection that occurs while in the firing line; and the other is reflection on action, which occurs after one has left the situation.

\section{Reflection in action}

The group facilitator needs to accommodate the activity plan during the group process. One facilitator reflected her own frustration over students' resistance to her plan to teach Chinese songs. After becoming conscious of the situation, she gave up her prepared songs and played the guitar while students wrote their homework. The process of reflection in action also occurred to another facilitator who decided to conduct a slow motion fighting game for students after she observed the uprising mood. The recognition of unexpected challenge immediately prompted the facilitator to improvise a new structure on the group.

Reflection in action also establishes cooperative relationships for the teachers within the group. By working together and seeking a suitable location for discussion, group members were initiated into informal dialogue, which built up the connection. 


\section{Reflection on action}

We reflected on what health care providers had done for the earthquake victims and readjusted the intervention model accordingly. We found that most post-earthquake relief activities for schoolteachers focused on intellectual (distress management conferences) and instrumental (food and other material supplies) needs rather than emotional support. Thus, therapy groups for survivors are best focused on emotional catharsis, rather than on health information.

Group facilitators also need to reflect on what they have communicated to the group, make modifications where necessary, and discuss their plan for the next group in another school. Reflection on action assists facilitators to integrate their experiential knowledge into the group through the process of developing effective strategies for the therapeutic use of the self. Facilitators reflected on the resistance they received from the first group during a 10-minute meditation after lunch. They meditated individually in an empty classroom away from the noise of other people and where distractions were less intrusive. This provided a rest by shunning external information and listening to the sound of voices in a trackless landscape. A result of this meditation was that facilitators discussed their approach and decided to let the members share in instead of lecturing them on the method of coping.

Group members reflected on the teaching strategies used after the earthquake. As they addressed the frustrations of teaching students as earthquake victims, the group facilitator invited members to share their experiences of managing classrooms after the earthquake. A range of alternative skills for facilitating learning in the classroom were exchanged in the group interaction. Through this group dialogue, frustrated teachers had an opportunity to express the difficulties they were experiencing. The teachers also shared their various strategies for handling their classes and received suggestions for coping with the students' problem behaviours. As a result, the teachers collectively solved their problems and moved away from their narcissistic self. At the same time, they relieved their emotional stress.

Reflection needs to occur both during and after the task in order to provide appropriate care and to modify facilitating strategies for the next task. Reflected caring is the attitude of accepting the natural world and letting it be itself. Caregivers providing reflected care could transcend egocentric judgements by being alert to the intricacies and embedded knowledge of their practice. They reflected in and on the practice with the intention of helping survivors to achieve a better balance in life. Reflection means throwing back thoughts and memories, in cognitive acts such as thinking, contemplation, meditation, and any other form of attentive consideration, in order to make sense of them, and to make contextually appropriate changes if they are required. ${ }^{16}$

\section{DISCUSSION}

The three types of caring practice described in this study can assist health practitioners to accommodate others as well as to monitor themselves. To be able to accommodate creatively is not derived from a subjective emotional attitude, but from intersubjective engagement and agreement. ${ }^{6}{ }^{17}$

Encumbered caring often hindered caregivers more than it helped them, for the following reasons: (1) caregivers focused on themselves, not on survivors; when "caring" arises from self-gratification, the methods of offering self are amiss; and (2) the methods of delivering care may be inappropriate for a given situation. Caring may be hurting or hampering survivors. Although a myriad of research results are available from the field of group therapy for trauma sufferers, the conclusions of this study are that, when faced with genuine cases of trauma, health care practitioners do not creatively accommodate themselves to meet the special demands of the situation, and that caregiving places survivors in undesirable situations. This has also been manifested in other studies. Stuhlmiller discussed how firefighters resented group debriefing, which occurred at the end of long work hours and delayed their rest. Ironically, the self-reflective approach to debriefing may have created stress for the firefighters, who were not accustomed to reflection. ${ }^{18}$ A study of American Red Cross personnel also addressed some workers' concerns about being labelled as "crazy" and who refused to attend a formal debriefing group. ${ }^{19}$ Furthermore, it has been suggested that debriefing "medicalises" normal distress. ${ }^{2021}$ A randomised controlled trial found psychological debriefing (1-hour debriefing intervention and written information) not only to be ineffective but also to impact adversely on the intervention group in terms of emotional distress, subjective reports of physical symptoms and physical functioning for pain, and interference with the normal activities of everyday life. ${ }^{20}$

Whereas disaster disconnects the self from others, and the self from the feeling of being in the world, a therapy group reconnects the self to others by dealing with concealed feelings. The feeling of being able to do something for others in connected caring easily falls into a reciprocal relationship that may not really meet the true otherness of the other during the complex path of healing. Van Manen has observed that Levinas 5 is the only philosopher who offers an ethic of caring responsibility that is founded in experiencing the otherness of the other. ${ }^{22}$ Levinas states that the approach to others is not originally in one's speaking out to the other, but in one's responsibility for him or her, which is elicited by the face of the other person. Responsibility for the other person should not require reciprocity. ${ }^{522}$

The solution to the egocentric carer may be "selfawareness" through reflection. The health care practitioner, as the actor on the stage, performs his or her role on the basis of his or her personal, professional self, and of reflection through interacting with the present audience. ${ }^{23}$ Reflecting is having the self-generated reflective view that was referred to by Kernberg as "the third" participant in a dialogue with the self, ${ }^{24}$ through which one can sufficiently and safely explore aspects of oneself through this outside self. The third combines objectivity with the perspectives of speaker and addressee/listener. ${ }^{25}$ The third is not only an observer, but can also be active in modifying the personality by being conscious of the context of self and others.

The function of the third can be understood as the mirror reaction in the group. Foulkes describes mirror reactions as follows:

\section{A person sees himself, or part of himself reflected in the interactions of other group members. He sees them reacting in the way he does himself, or in contrast to his own behaviour. ${ }^{26}$}

Reflection in the mirrors of others promotes self-regulation. Group facilitators found better ways to lead group interaction after reflection, using their past experiences and the attitudes of coworkers as mirrors. ${ }^{27}$ This praxis, corresponding to the dialectical relationship between the subjective and the objective, comes through a sensitivity to extrapsychic requiredness, which is a kind of Taoistic attitude. ${ }^{28}$ A Taoistic attitude is one of asking rather than telling. It means non-intruding, non-controlling, and noninterfering observation rather than a controlling manipulation. ${ }^{29}$ The Taoist, Juang-Tze (369-286 BC), used the metaphor of the intelligent mind as a mirror. He said: 
The mind of perfect man is like a mirror. It does not lean forward or backward in its response to things. It responds to things, but conceals nothing of its own. Therefore, it is able to deal with things without injury to its reality. ${ }^{30}$

The external reality is to be responded to naturally and faithfully, like a mirror objectively reflecting all, a kind of natural attitude. In the therapy group, this natural caring translates into trying not to treat people as if they have an illness, but letting them be. ${ }^{31}$ The deepest ethical motive of caring involves respect for the absolute dignity of the human being. Human dignity implies inner freedom and responsibility for one's own and others' lives. ${ }^{3}$ Reflected caring is not only doing good to others, but also transcending the self of the health care practitioner. Therefore, caring for the being of the other, the ethical consciousness, is born as the presence of a third party in the proximity of the one to the other. ${ }^{32}$

Reflected care is the deepest ethical motive of caring that comes from "a deeper self" of the caregiver. This deeper self needs an inner silence to listen and reflect. Periods of inner silence may be present during meditation. ${ }^{33}$ The group facilitators in this study took a break to meditate in order to connect the authentic self that brings an inner dialogue and then to discover the facilitating strategies that transcend encumbered caring. Reflected caring involves true generosity and consists precisely in fighting to destroy the causes that nourish false charity. ${ }^{33}$

\section{CONCLUSION}

While western bioethics focuses more on an individualistic, contractual, or legal view of caregiving relationships, this study indicated that caring relationships in Taiwanese culture are characterised by sharing and partnership, as reflected on Confucius's concept of "personhood".

Experiential accounts of caring in this study show the dimensions of caregiving, which will provide the framework for reflective clinical practice and promote an ethical attitude in health professionals. Three forms of caring activities were identified by using debriefing groups for earthquake survivors. The findings of this study were that reflected caring is pivotal to integrated and reciprocal relationships. Reflection on the relationship between patients and health professionals can produce a significant contribution to caring processes and caregiving relationships. Relational dialogue facilitating the development of the caring self relies essentially on the creation of an inner self that Kernberg named "the third position". ${ }^{24}$ The mirroring phenomenon that occurs in the interaction between the caregiver and the care recipient enhances the dialogue between the professional self and the personal self. Thus, the transformation of the professional self through the caring experience as described in this study can be achieved only through the conceptualisation of relational personhood.

\section{ACKNOWLEDGEMENT}

An earlier version of this article was presented at the 14th International Congress of the International Association of Group Psychotherapy, held in Jerusalem, Israel, in August 2000.

\section{Authors' affiliations}

H-H Chiang, Faculty of Nursing, National Yang-Ming University, Taipei, Taiwan
Z-Y Lu, Institute of Community Health Nursing, National Yang-Ming University, Taipei, Taiwan

S E Wear, Center for Clinical Ethics and Humanities, State University of New York at Buffalo, NY, USA

The authors thank the National Science Council (ROC) (NSC89-2314-B010-459) for partial funding for this project.

\section{REFERENCES}

1 Tsai DF-C. How should doctors approach patients? A Confucian reflection on personhood. J Med Ethics 2001;27:44-50.

2 Tsai DF-C. Ancient Chinese medical ethics and the four principles of biomedical ethics. J Med Ethics 1999;25:315-21.

3 Erikson K. Caring science in a new key. Nursing Science Quarterly 2002;15:61-5.

4 Schön DA. The reflective practitioner: how professionals think in action. New York: Basic Books, 1983.

5 Levinas E. Outside the subject. London: Athlone, 1993.

6 Chiang $\mathbf{H H}$, Chao Y. Intersubjectivity in the nurse-patient relationship. National Chengchi University Philosophical Journal 2001;7:307-21.

7 Bell JL. Traumatic event debriefing: service delivery designs and the role of social work. Social Work 1995;40:1-8.

8 Chemtob CM, Tomas S, Law W, et al. Postdisaster psychosocial intervention: a field study of the impact of debriefing on psychological distress. Am J Psychiatry 1997:154:415-7.

9 Shalev AY. Debriefing following traumatic exposure. In: Ursano RJ, McCaughey BG, Fullerton CS, eds. Individual and community responses to trauma and disaster: the structure of human chaos. New York: Cambridge University Press, 1994:201-19.

10 Barash D. The San Francisco earthquake: then and now. Perspectives in Psychiatric Care 1990;26:32-9.

11 Marcel G. Being and having. Boston, MA: Beacon, 1951:154-78.

12 Lee Y-T. Health promotion program of Luku township after 921 earthquake. Taipei: National Yang-Ming University, Institute of Health and Welfare Policy, 2000.

13 Benner P. Parents' caring practices with schizophrenic offspring. In: Benner P, eds. Interpretative phenomenology. London: SAGE, 1994:167-84.

14 Benner $\mathbf{P}$. The tradition and skill of interpretative phenomenology in studying health, illness and caring practice. In: Benner $P$, ed. Interpretative phenomenology. London: SAGE, 1994:99-127.

15 Spiegelberg H. The phenomenological movement. The Hague: Martinus Nijhoff, 1965.

16 Taylor BJ. Reflective practice. Buckingham: Open University Press, 2001.

17 Widdershoven GAM. Care, cure and interpersonal understanding. J Adv Nurs 1999;29:1163-9.

18 Stuhlmiller CM. Occupational meanings and coping practices of rescue workers in an earthquake disaster. West J Nurs Res 1994;16:268-87.

19 Armstrong K, Zatzick D, Metzler T, et al. Debriefing of American Red Cross personnel: pilot study on participants' evaluations and case examples from the 1994 Los Angeles earthquake relief operation. Soc Work Health Care 1998;27:33-50.

20 Mayou RA, Ehlers A, Hobbs M. Psychological debriefing for road traffic accident victims. Br J Psychiatry 2000;176:589-93.

21 Kenardy J. The current status of psychological debriefing. It may do more harm than good. BMJ 2000;321:1032-3.

22 Van Manen M. Care-as-worry, or "Don't worry, be happy". Qualitative Health Research 2002;12:262-78.

23 Chiang $\mathrm{H}-\mathrm{H}$, Chang P-F, Chao Y-M. The exploration of practicing nursing ethics from creating the roles of nurse. Philosophical Forum 2001;37:88-103.

24 Kernberg OF. The nature of interpretation: intersubjectivity and the third position. Am J Psychoanal 1997;57:293-312.

25 Sumner J. Caring in nursing: a different interpretation. J Adv Nurs 2001;35:926-32.

26 Foulkes SH. Therapeutic group analysis. London: Maresfield Reprints, 1984.

27 Chiang HH, Tseng WC, Lu ZY. The mirror phenomena in clinical group supervision for psychiatric nurses. Proc Natl Sci Counc Repub China C 1997;7:363-70.

28 Maslow A. The farther reaches of human nature. New York: Arkana, 1971:259-69.

29 Maslow A. The farther reaches of human nature. New York: Arkana, 1971:3-23.

30 Chan W-T. A source book in Chinese philosophy. Princeton, NJ: Princeton University Press, 1963.

31 Campbell J. The dangerous present: bridging past and future. Group Analysis 2000;33:179-91.

32 Levinas E. Entre nous: on thinking-of-the-other. New York: Columbia University Press, 1998

33 Besmer B. Psychosynthesis: height psychology-dis-covering the self and the Self. Interpersonal Development 1973;4:215-25. 